\title{
CONCEPÇÃO AMBIENTAL NA EDUCAÇÃO BÁSICA: SUBSÍDIOS PARA ESTRATÉGIAS DE EDUCAÇÃO AMBIENTAL
}

\author{
Cláudio Sérgio Estevam ${ }^{1}$ \\ Marília Carla de Mello Gaia ${ }^{2}$
}

Resumo: Este trabalho analisa as concepções de Ambiente e Educação Ambiental de estudantes da Educação Básica, com vistas a possibilitar intervenções de um projeto de extensão voltado para Educação Ambiental a partir do contexto dos sujeitos envolvidos. Teve com objeto de estudo 31 alunos e duas professoras de uma escola pública da região metropolitana de Belo Horizonte. Foi realizada uma sondagem diagnóstica, para posterior análise e categorização das concepções encontradas. Tal fato possibilitou o planejamento de ações que resultaram em palestra, trilha ecológica, informações e discussões em sala verde de forma contextualizada. O estudo permitiu inferir que o conhecimento prévio das concepções ambientais do público alvo, possibilita a elaboração de estratégias contextualizadas de Educação Ambiental.

Palavra-chave: Transversalidade; Percepção Ambiental; Ensino de Ciências.

\footnotetext{
${ }^{1}$ Centro Universitário Metodista Izabela Hendrix, MG. E-mail: estevam.bio@gmail.com

2 Universidade Federal de Santa Catarina, SC. E-mail: marilia.gaia@ufsc.br
} 


\section{Introdução}

Para se entender a Educação Ambiental (EA) é preciso pensar na importância da divulgação e construção de conhecimentos sobre as questões ambientais, tal como, o resultado da Conferência de Estocolmo. Esta possibilitou a Conferência de Tbilisi, em 1977, onde ficou definido o conceito de EA como um processo de atitudes em relação ao meio que possibilita o entendimento das inter-relações, promovendo mudanças de atitudes, abrangendo os seres humanos em seus aspectos culturais, biológicos e políticos, permitido assim uma tomada de decisão consciente (TOZZONI-REIS, 2002). Para Jacobi (2003), a EA pode ser definida como um recurso necessário para a modificação de uma crescente degradação socioambiental, ela transforma e co-responsabiliza os sujeitos envolvidos buscando promover um desenvolvimento sustentável.

A EA na Educação Básica está diretamente ligada à concepção ambiental dos discentes e docentes envolvidos nesse processo, bem como aos recursos disponíveis para que esse trabalho de transformação de consciência ambiental seja desenvolvido (JACOBI et al., 2009). Pensando nisto e na estrutura do ambiente escolar, é preciso permear por fatos importantes que marcaram a composição do currículo escolar, como a Lei de Diretrizes e Bases da Educação Nacional (LDB), Parâmetros Curriculares Nacionais (PCN's) e Temas Transversais (TT's). As ações de educação englobam os processos de formação, que se desenvolvem durante a vida familiar e em diversos momentos da vida social do indivíduo (BRASIL, 1996).

Os PCNs são referenciais de qualidade para a educação no ensino em todo o Brasil. Eles não são o currículo acabado e obrigatório, mas o seu grau de detalhes os torna parte importante do currículo do Ensino Fundamental, seu objetivo é padronizar o ensino no país. Funcionam como documento que norteia o currículo escolar com o objetivo de garantir a todas as crianças e jovens brasileiros, o direito de usufruir de conhecimentos que são adotados como imprescindíveis para o exercício da cidadania (MACEDO, 1998). Os PCN's preveem seis TT's: Ética, Meio Ambiente, Trabalho e Consumo, Orientação Sexual, Saúde e Pluralidade Cultural. Estes foram definidos por serem considerados questões sociais relevantes, atuais e urgentes, com alcance nacional e até mesmo universal. Porém, não assumidos como disciplinas isoladas, os TT's devem ser tratados como temas que transcorrem por todas as disciplinas (BOMFIM et al., 2013).

Segundo Macedo (1988), os PCN's assumem que determinados temas têm mais afinidades com certas áreas e por isso devem ser mais explorados. A partir disso, é possível entender que a EA pode ser trabalhada na Educação Básica utilizando desses TT's para abordar as questões ambientais. Estas questões podem e precisam estar integradas às práticas cotidianas da escola. Então, de maneira articulada, a EA serve como mediadora entre os TT's e as relações educativas que esta estabelece, influenciando de forma crítica e emancipatória o aprendizado e permitindo que esse ocorra de forma transversal e interdisciplinar. 
A EA não pode ser trabalhada de maneira descontextualizada e pontual. Os PCN's orientam que a mesma seja trabalhada de forma transversal, perpassando pelas diferentes disciplinas, não se limitando às tradicionais disciplinas de Ciências/Biologia e Geografia (BOMFIM et al., 2013). Para Jacobi (2003), o saber contido em áreas distintas origina conceitos e conhecimentos heterogêneos e a EA possibilita 0 envolvimento de várias áreas do conhecimento. Assim a EA na escola deve passar por um enfoque multirreferencial, partindo de um ponto de vista onde a abertura de um espaço contemple o diálogo de diferentes abordagens.

A EA deve fazer sentido para o sujeito, precisa romper barreiras estruturais existentes no currículo escolar e fazer pontes com a realidade, de modo que o sujeito ao aprender também possa ensinar (ALMEIDA; OLIVEIRA, 2007). Tal fato corrobora com Tozzoni (2006) que discute a necessidade da escola trabalhar com o aluno o que acontece em sua volta, preparando o discente para a construção de um discurso crítico dos fatos que ocorrem em seu cotidiano. Neste contexto a EA se torna uma ferramenta de ensino libertadora com força passível de criar sujeitos com pensamento crítico e reflexivo.

De acordo com o Ministério da Educação e Cultura (BRASIL, 2005), as instituições de ensino devem ser incitadas para o trabalho educativo "[...] com a pedagogia de projetos e promovendo a integração entre as diversas disciplinas". Assim, torna-se explícita a necessidade da inclusão de novas estratégias pedagógicas, dentre as quais é possível apontar a pedagogia de projetos. Contudo, é necessário que esta prática por meio de projetos seja cíclica, crítica, contextualizada, interdisciplinar e comprometida com a aquisição de conhecimentos (TOZONI-REIS, 2006). Confirmando o que demonstrou Matos (2009) que ao trabalhar a EA por meio de projetos em uma escola municipal, constatou que tal metodologia rompe as barreiras do ensino o tradicional e possibilita uma expressão reflexiva da postura pedagógica. Isto permite que o estudante tenha participação ativa na construção do conhecimento.

Nessa perspectiva, levantou-se a hipótese de que o conhecimento prévio das concepções de Ambiente e de EA dos sujeitos envolvidos no processo educativo possibilita intervenções e estratégias contextualizadas, que promovem a construção de sujeitos críticos e reflexivos, além de propiciar caminhos para ações educativas efetivas.

A migração da população do campo para os centros urbanos, entre outros fatores, coopera para o estabelecimento de precárias condições de vida para a população local e como consequência uma crise ambiental nas cidades (JACOBI, 2003). Assim, ao refletir sobre as práticas ambientais e a degradação ocorrida em diversos ambientes, nota-se a necessidade de uma intervenção ambiental contextualizada e sistêmica (TOZONI-REIS, 2002).

Segundo Jacobi et al. (2009), práticas de sustentabilidade contextualizadas fortalecem valores coletivos e solidários. $E$ isto pode ancorar a escola e outros ambientes educativos na realização de ações reflexivas sobre a problemática ambiental. Para tanto, é preciso um enfoque mais amplo, 
projetando para a sociedade a necessidade de ações educativas que envolvam a EA na escola de maneira que as questões ambientais sejam trabalhadas de forma interdisciplinar e contextualizadas com a realidade do educando (MARINHO, 2004).

Dessa forma, o presente trabalho teve como objetivo identificar e analisar a concepções de Ambiente e EA de estudantes da Educação Básica, com vistas a possibilitar intervenções de um projeto de extensão universitária de EA a partir do contexto dos sujeitos envolvidos.

\section{Concepção ambiental}

Segundo Oliveira et al., (2007) a busca por uma definição da concepção de Ambiente e EA pode gerar divergências, pois existem opiniões estruturadas em um meio ambiente apenas situado na natureza, desconsiderando como Ambiente os espaços urbanos. Isso pode gerar uma dificuldade limitadora, que nos aplica a pena de uma definição equivocada de Ambiente e EA.

Para Silva (2008), é possível identificar concepções de Ambiente através de conceitos apresentados por uma determinada população. Essas concepções são importantes, pois, vão influenciar a execução das ações ambientais.

Segundo Mortimer (1996), um sujeito pode em seu discurso atribuir vários significados e representações à realidade à sua volta, possibilitando a coexistência de diferentes concepções que construirão seu perfil conceitual. Assim, as ações de EA precisam contribuir para que os sujeitos incorporem novas ideias científicas a cerca de Ambiente, as utilizando nos contextos necessários e ampliando sua concepção ambiental.

De acordo com Sauvé (1997), é possível identificar várias concepções de Ambiente, estas estão classificadas em seis categorias descritas no Quadro 1.

Quadro 1: Concepções sobre o meio ambiente na Educação Ambiental.

\begin{tabular}{|c|c|c|}
\hline Ambiente & Relação & Características \\
\hline Como natureza & $\begin{array}{l}\text { Para ser apreciado e } \\
\text { preservado }\end{array}$ & $\begin{array}{l}\text { Natureza como catedral ou como um } \\
\text { útero, pura e original }\end{array}$ \\
\hline Como recurso & Para ser gerenciado & $\begin{array}{l}\text { Herança biofísica coletiva, qualidade } \\
\text { de vida }\end{array}$ \\
\hline Como problema & Para ser resolvido & $\begin{array}{l}\text { Ênfase na poluição, deterioração e } \\
\text { ameaças }\end{array}$ \\
\hline $\begin{array}{l}\text { Como lugar para } \\
\text { viver }\end{array}$ & $\begin{array}{l}\text { Educação Ambiental } \\
\text { para cuidar do ambiente }\end{array}$ & $\begin{array}{l}\text { A natureza com os seus componentes } \\
\text { sociais, históricos e tecnológicos }\end{array}$ \\
\hline Como biosfera & $\begin{array}{l}\text { Como lugar para ser } \\
\text { dividido }\end{array}$ & $\begin{array}{l}\text { Espaçonave Terra Gaia, a } \\
\text { interdependência dos seres vivos com } \\
\text { os inanimados }\end{array}$ \\
\hline $\begin{array}{l}\text { Como projeto } \\
\text { comunitário }\end{array}$ & Para ser envolvido & $\begin{array}{l}\text { A natureza como foco na análise } \\
\text { crítica na participação política da } \\
\text { comunidade }\end{array}$ \\
\hline
\end{tabular}

Fonte: Sauvé (1977). 
Soares e Frenedozo (2009), ao analisarem as concepções de professores da cidade de Santo André (SP), identificaram as concepções relacionadas ao Ambiente como biosfera e como lugar para se viver, corroborando com as concepções apresentadas por Sauvé (1997). Levantaram ainda 0 fato de que a localização onde os professores trabalham, exerça influência sobre as distintas concepções apresentadas por estes. Neste ponto, os autores apontaram que os professores que trabalhavam próximo a curso d'água e matas possuíam uma concepção de Ambiente mais relacionada à biosfera, enquanto os professores que trabalhavam em ambientes mais urbanizados apresentaram uma concepção relacionada ao lugar para se viver.

Lacerda e Oliveira (2012) também discutem as diferentes concepções existentes sobre Ambiente e EA ao analisarem a concepção ambiental de estudantes de cursos técnicos. Observaram que os estudantes apresentaram uma concepção de EA Conservacionista e Integrada. A concepção Conservacionista estava relacionada com a ideia de não poluir e preservar o que é natural; e a concepção Integrada foi relacionada ao homem e suas interações com o ambiente natural e urbano.

$\mathrm{Na}$ perspectiva de identificar as diferentes linhas de tensões e conflitos que definem Ambiente e EA entre professores de Ciências do Ensino Fundamental, Oliveira e colaboradores (2007) explicitam três tipos diferentes de concepções de EA, descritas no Quadro 2.

Quadro 2: Diferentes concepções de Educação Ambiental.

\begin{tabular}{|c|c|}
\hline Concepção & Características \\
\hline $\begin{array}{l}\text { Tradicional/ } \\
\text { Simplista }\end{array}$ & $\begin{array}{l}\text { Predomina a ideia simplista e tradicional de prevenção ou } \\
\text { conservação da natureza }\end{array}$ \\
\hline Integradora & $\begin{array}{l}\text { Estimula o questionamento e o senso crítico pautado na percepção } \\
\text { do indivíduo do meio e de suas interações de forma integral }\end{array}$ \\
\hline $\begin{array}{l}\text { Resolução } \\
\text { problemas }\end{array}$ & $\begin{array}{l}\text { Desperta o interesse e a preocupação com a solução de problemas } \\
\text { ambientais, buscando criar agentes de mudanças que multipliquem } \\
\text { ações como solução para os problemas ambientais }\end{array}$ \\
\hline
\end{tabular}

Fonte: Adaptado de Oliveira et al. (2007).

Segundo Valentin e Santana (2010), é preciso levar em conta as diversas concepções de EA, pois essas influenciam as práticas e orientam as ações relacionadas às questões ambientais. Neste contexto, estudar as concepções dos professores e seus alunos implica em salientar os valores, motivações e as principais linhas dos pensamentos dos indivíduos fundamentais envolvidos no processo educativo. 


\section{Percurso metodológico}

Este trabalho foi desenvolvido através de sondagem diagnóstica sobre concepção ambiental de estudantes e professoras da Educação Básica e posterior intervenção ambiental a partir das informações e contexto destes.

As atividades deste estudo são parte integrante de um projeto de extensão em EA desenvolvido por uma instituição de ensino superior, sendo suas atividades realizadas junto a escolas públicas e particulares da região metropolitana de Belo Horizonte (Minas Gerais).

O referido projeto de extensão universitária, iniciado em 2009, tem como objetivo promover ações de EA em escolas públicas, visando estabelecer uma estratégia de EA para a comunidade local, para os estudantes universitários e extensionistas. Além de promover diversas atividades realizadas em escolas envolvidas no projeto, como oficinas, minicursos e palestras, parte das atividades do projeto é desenvolvida em uma Unidade da instituição de ensino superior localizada na região metropolitana de $\mathrm{BH}$, por meio de trilhas ecológicas. As trilhas ecológicas foram desenvolvidas para permitirem o contato dos visitantes com elementos que compõem os recursos naturais encontrados na Unidade, que tem em sua vegetação elementos típicos do Cerrado e da Mata Atlântica.

As atividades aqui analisadas foram desenvolvidas entre setembro e outubro de 2013, com estudantes de uma escola pública da região metropolitana de Belo Horizonte. A escolha dos referidos estudantes se deu a partir do interesse da escola em participar das atividades educativas do projeto de extensão universitária.

Os sujeitos deste trabalho são duas professoras, uma de Educação Física, outra de Matemática, e trinta e um estudantes da Educação Básica. Os estudantes, com idade média de 13 anos, estudam no período da tarde e no período da manhã estão envolvidos em ações do contra turno escolar (educação integral) - período o qual as atividades aqui analisadas foram desenvolvidas, estas foram executadas em quatro momentos distintos.

Em um primeiro momento foi realizada uma visita à escola selecionada $\mathrm{e}$ aplicada uma sondagem diagnóstica aos estudantes e professoras sujeitos desta pesquisa, sobre seus conhecimentos a cerca de Ambiente e EA.

As perguntas da sondagem aplicada aos estudantes foram: $O$ que é meio ambiente? O que é Educação Ambiental? Em sua opinião para que serve a Educação Ambiental? Na sua escola, a Educação Ambiental é trabalhada por todos os seus professores? Como? Você acha que a Educação Ambiental, deveria ser constituída uma disciplina do seu currículo escolar, como as demais disciplinas?

As perguntas da sondagem aplicada às professoras foram: Em sua opinião o que é meio ambiente? Qual é a sua concepção de Educação Ambiental? Você trabalha Educação Ambiental em sua disciplina? Você acha 
que a Educação Ambiental, deveria ser constituída uma disciplina do currículo escolar, como as demais disciplinas? Por quê? Qual sua maior dificuldade ou limitação para trabalhar a Educação Ambiental com seus alunos?

Segundo Rosa (2008), a sondagem funciona como uma ferramenta que permite o conhecimento prévio dos saberes do estudante sobre determinado tema e isto possibilita o planejamento de ações direcionadas. Então a sondagem dos conhecimentos prévios dos estudantes teve como objetivo direcionar as atividades do projeto de maneira a atender as demandas de formação. Para tanto, a palestra e a visita ao espaço de preservação ambiental foram orientadas pelas respostas da sondagem.

Neste trabalho foram utilizadas citações de professores e estudantes sujeitos desta pesquisa. As citações foram obtidas através da sondagem diagnóstica, os professores foram identificados com a letra $(P)$ e os estudantes com a letra $(A)$.

Em um segundo momento foi realizada a análise e interpretação dos resultados apresentados na sondagem.

Em um terceiro momento foi realizada uma palestra construída a partir das informações levantadas na sondagem diagnóstica executada anteriormente. Esta palestra possibilitou a apresentação do projeto de extensão universitária disponibilizando a concepção de EA que este adota, a referida atividade teve duração aproximada de uma hora.

Em um quarto momento, os estudantes envolvidos realizaram uma visita ao espaço de preservação ambiental onde o projeto de extensão desenvolve suas atividades. Neste espaço foi realizada uma trilha ecológica interpretativa e informações em Sala Verde - sala onde se encontram exsicatas de alguns exemplares de plantas e maquetes de insetos, feitas por graduandos do curso de Ciências Biológicas da instituição de ensino superior.

\section{Resultados e discussão}

Corroborando com Claudino (1977), que descreve a sondagem como um atributo capaz de proporcionar ao educador meios de conhecer o seu público e direcionar suas ações educativas, os estudantes foram questionados sobre 0 que é o meio ambiente. Neste momento foram identificadas duas concepções de Ambiente: uma concepção Conservacionista e uma concepção Integrada, como proposto por Lacerda e Oliveira (2012).

As diferentes concepções de meio ambiente encontradas entre os alunos que participaram desta pesquisa foram assim organizadas: $66 \%$ dos alunos demonstraram possuir uma concepção Conservacionista, enquanto, $34 \%$ uma concepção Integrada. Para exemplificar a concepção Conservacionista podemos destacar: 
O meio ambiente é onde nascem e crescem as árvores, como no Amazonas. É a fauna, flora, florestas e precisa ser preservado (A1).

O meio ambiente é um lugar cheio de árvores bichos, flores e etc... (A2).

É um lugar lindo, cheio de árvores, que precisa ser preservado (A3).

No caso de uma concepção Integrada temos:

O meio ambiente é onde moro, as ruas, lagoa, fauna e flora, é tudo (A4).

É o lugar onde moramos e a natureza (A5).

O meio ambiente é o lugar onde as pessoas e animais vivem (A6).

Quando questionados sobre o que é a EA e qual sua importância, 100\% dos estudantes apresentaram uma concepção Tradicional/Simplista, mais relacionada à preservação ou conservação da natureza, como proposto por Oliveira et al., (2007). O aluno A4, foi incluído na concepção Integrada enquanto definia o que era meio ambiente. Era esperado que este estudante possuísse uma concepção Integradora de EA, porém como os demais, ele demonstrou uma concepção Tradicional/Simplista enquanto definia o que é e para que serve a EA.

Educação Ambiental é ensinar a não desmatar não colocando em risco o meio ambiente. (A4).

Tal fato corrobora com Mortimer (1996), sobre a coexistência de duas ou mais concepções em um mesmo indivíduo, neste caso especificamente, a concepção de EA. O autor sugere a possibilidade de o indivíduo possuir diferentes formas de pensar sobre o mesmo objeto em diferentes domínios científicos. Além disso, confirma a importância da sondagem para direcionar as ações a fim de atender de forma significativa os sujeitos envolvidos.

Com vistas a identificar como os estudantes percebem a importância da EA e como esta é trabalhada em sua escola, foi perguntado se a EA era trabalhada por todos os seus professores, e se eles acham que esta deveria ser constituída uma disciplina do currículo escolar como as demais disciplinas. Dos estudantes envolvidos, $3 \%$ não responderam a questão, $6 \%$ não souberam se 
posicionar a respeito e um total de $91 \%$ responderam que a EA era trabalhada por todos os seus professores, geralmente em temas como lixo ou desmatamento e responderam que gostariam da inclusão da EA como disciplina do currículo escolar, associando esta inclusão ao prazer de estar em contato com a natureza.

Tal fato reflete a concepção de meio ambiente da professora (P1), responsável pela turma e que os acompanhava durante a atividade. Esta, quando questionada sobre o que é meio ambiente, demonstrou uma concepção Conservacionista.

Meio ambiente envolve fauna e flora, ou seja, o nosso planeta e tudo o que respira e se movimenta nele [...]. Precisamos ter em mente a necessidade de preservar e conservar o nosso meio ambiente (P1).

Isto também é confirmado por Júnior e Tomanik (2013) ao relatarem que conhecer as representações sociais dos docentes sobre temas ambientais possibilita um melhor entendimento dos caminhos de sua prática social e esta indica o caminho aos discentes.

Segundo Fernandes et al., (2002), no antropocentrismo a natureza tem valor quando é útil para o homem, ela se torna posse e passa a ser um direito ao qual o homem possui para sua sobrevivência, utilização científica e ou tecnológica. Neste sentido, foi perguntado às professoras se elas concordam que a EA deveria ser constituída uma disciplina do currículo escolar. As professoras responderam que sim, relacionando a EA a preservação de maneira antropocêntrica.

A EA deveria ser constituída uma disciplina do currículo escolar por que precisamos ter em mente a necessidade de preservar $e$ conservar o nosso meio ambiente para nossa sobrevivência (P1).

A EA deveria ser constituída uma disciplina do currículo escolar, pois, na minha opinião é importante ter mais tempo de reflexão para esse assunto, afinal ele está ligado a nossa sobrevivência no planeta (P2).

Ao refletir sobre as dificuldades das questões ambientais é possível entender que de certa forma a falta de conhecimentos sobre esta temática pode dificultar o trabalho dos professores, pois, o embasamento teórico possibilita fundamentação da prática (JÚNIOR; TOMANIK, 2013). Nesta perspectiva, foi 
perguntado às professoras qual era a maior dificuldade ou limitação em trabalhar a EA, e corroborando o fato acima mencionado, a resposta de uma das professoras se baseou em capacitação profissional.

Minha maior dificuldade em trabalhar a $E A$,
é material didático, cursos, enfim,
preparação (P2).

Segundo Mortimer (1996), as diferentes formas de um indivíduo ver e representar a realidade são influenciadas pelo contexto a sua volta. Neste sentido e pelos aspectos levantados nos relatos dos estudantes, notou-se que o contato com a realidade e o desenvolvimento do trabalho de EA pode contribuir para a reconstrução de conhecimentos e para a evolução das concepções discentes. Possibilitando assim a criação de novos valores diante da relação homem/ambiente.

Assim, durante a palestra realizada após a sondagem foram sendo apresentadas as concepções de Ambiente e EA adotadas pelo referido projeto de extensão universitária, com intuito de possibilitar um avanço das concepções apresentadas pelos alunos, para além de uma concepção Conservacionista restrita ao ambiente em meio à natureza e para além de uma concepção Tradicional/ Simplista de EA. Desta forma, é viabilizado aos sujeitos o avanço para a construção de uma concepção crítica que aponte para as transformações da sociedade na direção de novos paradigmas de justiça social e qualidade ambiental (GUIMARÃES, 2000).

Para Jacobi (2003) é imprescindível a execução de práticas sociais que fortaleçam e promovam meios de acesso a uma EA integradora. Assim, na palestra foi discutida uma concepção Integradora, onde os sujeitos puderam visualizar as interações homem/ambiente de maneira integral. Para exemplificar os diversos tipos de ambientes, durante a palestra foram apresentadas intervenções anteriormente realizadas em outras escolas, parques e ações de EA no trânsito. Dessa forma se estimulou o questionamento dos estudantes, 0 que permitiu uma expansão do entendimento destes sobre as diferentes concepções de Ambiente e EA.

Segundo Schall (1994), cada ação pode provocar uma reação em alguém ou no meio ambiente, que por sua vez lançará sua resposta. Considerando essa afirmativa é possível entender que a EA pode criar nos estudantes um senso crítico e reflexivo acerca do meio ambiente à sua volta. Desta forma, a visita dos estudantes ao espaço de preservação ambiental, foi efetuada numa perspectiva crítica a fim de contemplar uma realidade mais complexa, onde estes pudessem perceber o conjunto de inter-relações entre o ser humano e o ambiente. 
Segundo Jacobi (2003), é preciso trabalhar de forma interdisciplinar promovendo uma transformação na consciência sobre a importância da relação do ser humano com o meio ambiente, seja este em pontos ecológicos ou urbanos, proporcionando assim uma vida saudável, permeando entre temas ligados a preservação e na influência direta dessa para a manutenção da vida. Nesta perspectiva, o grupo realizou uma trilha ecológica interpretativa, onde foram sendo abordados diversos temas e pontuadas as consequências das ações antrópicas da comunidade do entorno. Os extensionistas do projeto realizaram paradas ao longo da trilha e nestes momentos passavam informações para os estudantes sobre bioindicadores, água, políticas públicas e diversos temas pré-estabelecidos ou que apareciam como demandas dos estudantes e permitiam a interação destes na construção do conhecimento. Os estudantes tiveram a oportunidade de expor suas concepções e contrasta-las com as diferentes concepções apresentadas. A trilha ecológica possui espaços que se chocam com ambientes urbanos, isso permitiu uma abordagem dos diferentes tipos de ambientes e a apresentação de uma concepção ambiental crítica e reflexiva apresentada pelo projeto, que segundo Guimarães (2000) é capaz de apontar caminhos para o desenvolvimento do sujeito crítico.

O grupo recebeu informações no ambiente denominado Sala Verde, tiveram contato com várias maquetes de insetos que foram construídas por estudantes universitários de Ciências Biológicas. Esta situação também permitiu a abordagem de diferentes concepções de Ambiente e EA, visto que a maioria dos insetos era conhecida pelo grupo e coabitam os diferentes ambientes explorados pelos seres humanos.

$\mathrm{Na}$ Sala Verde foram explorados os diferentes ambientes habitados pelos insetos como moscas, mosquitos, barbeiros e as doenças que estes transmitem com um enfoque maior sobre o Aedes aegypti. Isto possibilitou uma discussão que envolveu o levantamento de soluções por parte do grupo para questões como, meios de prevenção, ações educativas e políticas públicas no controle da Dengue. Tal fato é corroborado por Silva (2008) que define a EA como um processo de educação onde o educando participa de maneira crítica, visando questões sociais culturais e econômicas. O grupo pode observar exsicatas e obter algumas informações sobre elementos do Cerrado e Mata Atlântica; puderam visualizar uma foto da propriedade percebendo como o fragmento de vegetação esta cercada por casas da comunidade local e discutir os impactos relacionados.

\section{Algumas considerações}

A EA funciona como uma ferramenta mediadora entre os TT's e as relações de conscientização e contextualização que esta estabelece. Neste contexto, é possível entender que, por mais que recebamos estímulos externos, a transformação acontece no interior de cada um, mas pode ser influenciada quando nos sentimos tocados a aprender. Conseguimos entender quem somos, quando entendemos quem é o ambiente a que integramos. 
Nesta perspectiva, no trabalho com a EA é de extrema importância o conhecimento prévio das concepções ambientais dos sujeitos envolvidos (estudantes ou não), a fim de guiar as ações educativas de maneira a produzir um conhecimento significativo. Uma concepção ambiental equivocada pode resultar em ações limitadas ou ineficientes. As concepções são influenciadas pelo contexto, portanto, podem existir diversas concepções de Ambiente e EA como foi apresentado neste trabalho. Levando em conta a complexidade do tema não é possível considerar que apenas uma concepção consiga explicar as diferentes representações dos estudantes sobre Ambiente e EA. E preciso uma interação entre as diversas concepções existentes para que estas se influenciem mutuamente.

A sondagem realizada neste trabalho possibilitou o planejamento de ações que resultaram em uma palestra, trilha ecológica e informações/discussões na Sala Verde. Estas ações direcionadas pela sondagem contribuíram de forma crítica para a ampliação das concepções de Ambiente e EA dos sujeitos envolvidos. Confirmando a hipótese de que o conhecimento prévio das concepções de Ambiente e de EA dos sujeitos envolvidos no processo educativo possibilita intervenções e estratégias contextualizadas que promovem a construção de sujeitos críticos e reflexivos, além de propiciar caminhos para ações educativas mais efetivas.

As dificuldades de alguns professores em tratar questões de EA podem ser superadas por meio de uma postura interdisciplinar crítica e reflexiva que dialogue com as interações entre a sociedade e o ambiente. O professor é o mediador do conhecimento envolvido no processo de aprendizado e as sínteses de suas representações dizem respeito às diferentes concepções de EA. Para trabalhar a EA na Educação Básica é necessário reconhecer que a extensão das questões ambientais configura-se crescentemente em um conjunto de sujeitos que integram o universo educativo. Dessa forma, é possível reconhecer os múltiplos campos do saber e as complexidades que envolvem as questões interdisciplinares relacionadas à EA.

Portanto, como ponto a ser melhorado na execução da EA na Educação Básica, foi percebido a ausência de capacitação dos professores no que diz respeito as questões ambientais visto que as ações em EA podem refletir as concepções dos docentes. Tal procedimento permitiria a construção de sujeitos críticos e reflexivos, capazes de mediar o conhecimento relacionado às questões ambientais. Desta forma os estudantes desenvolveriam a capacidade de realizar ações de EA de forma reflexiva, expressando sua opinião de forma livre e consciente. 


\section{Referências}

ALMEIDA, M.P.Q; OLIVEIRA, C.I. Educação Ambiental: Importância da atuação efetiva da escola e do desenvolvimento de programas nesta área. Revista Eletrônica do Mestrado em Educação Ambiental, v. 18, p.12-24, jan. 2007.

BRASIL. LDB - Lei no 9394/96, de 20 de dezembro de 1996. Ministério de Educação e Cultura. Brasília: MEC, 1996. Disponível em: $<$ portal.mec.gov.br/arquivos/pdf/ldb.pdf>. Acesso em: 27 out. 2013.

BRASIL. Ministério da Educação; Ministério do Meio Ambiente. Programa Nacional de Educação Ambiental. Brasília, 2005. Disponível em: $<$ http://portal.mec.gov.br/secad/arquivos/pdf/educacaoambiental/pronea3.pdf > Acesso em: 14 de mar. de 2014.

BOMFIM, A.M. et al . Parâmetros curriculares nacionais: uma revisita aos temas transversais meio ambiente e saúde. Trabalho, educação e saúde. Rio de Janeiro, v. 11, n. 1, p. 27-52, 2013.

FERNANDES, E.C; CUNHA, A.M.O; JÚNIOR, O.M. EDUCAÇÃO AMBIENTAL E MEIO AMBIENTE:Concepções de profissionais da educação. Anais do II ENCONTRO NACIONAL DE PESQUISADORES EM EDUCAÇÃO AMBIENTAL, UFU, São Carlos, Minas Gerais, 2002. Disponível em: $<$ http://fep.if.usp.br/ profis/arquivos/ivenpec/Arquivos/Painel/PNL123.pdf>.

Acesso em: 28 out. 2014.

GUIMARÃES, M. EDUCAÇÃO AMBIENTAL: No consenso um embate? Campinas, São Paulo. p 67-85. Editora: Papirus 2000.

JACOBI, P. Educação ambiental, cidadania e sustentabilidade. Cadernos de Pesquisa. São Paulo, n. 118, p. 189-206, mar. 2003.

JACOBI, P.R; TRISTÃO, M.; FRANCO, M.I.G.C. A função social da Educação Ambiental nas práticas colaborativas: Participação e engajamento. Cad. Cedes, Campinas, vol. 29, n. 77, p.63- 79, Jan./Abr. 2009.

JÚNIOR, C.A.O.M; TOMANIK, E.A. Representações sociais de meio ambiente: subsídios para a formação continuada de professores. Ciência \& Educação. (Bauru), v. 19, n. 1, p. 181-199, 2013.

LACERDA, K.A.P; OLIVEIRA, S.L. Análise de concepção ambiental dos alunos dos cursos integrados do IFG campus Jataí. Anais do VII Encontro Nacional de Pesquisa em Educação em Ciências-ENPEC, atas do ENPEC, Florianópolis, nov. 2009. Disponível em: $<$ http://posgrad.fae.ufmg.br/posgrad/viienpec/pdfs/124.pdf >. Acesso em: 26 Set. 2014.

MACEDO, E.F. Os temas transversais nos Parâmetros Curriculares Nacionais. v. 8, p. 23-27, nov.1998. Disponível em: $<$ http://www.cienciamao.usp.br/tudo/exibir.php? midia=qne\&cod= espacoabertoo stemastrans>. Acesso em: 01 nov. 2013. 
MARINHO, A.M.S. A Educação Ambiental e o desafio da interdisciplinaridade. Dissertação (Mestrado) - Pontifícia Universidade Católica de Minas Gerais, 2004.

MATOS, M.A.E. A metodologia de projetos, a aprendizagem significativa e a Educação Ambiental na escola. Ensino de Saúde e Ambiente, v. 2, n. 1, p. 2229.

MORTIMER, E.F. Construtivismo, mudança conceitual e ensino de ciências: para onde vamos. Investigações em Ensino de Ciências- v1(1), p.20-39, 1996.

OLIVEIRA, A.L; OBARA A.T; RODRIGUES, M.A. Educação ambiental: Concepções e práticas de professores de ciências do ensino fundamental. Revista Electrónica de Enseñanza de las Ciencias Vol. 6, №3, p.471-495, 2007.

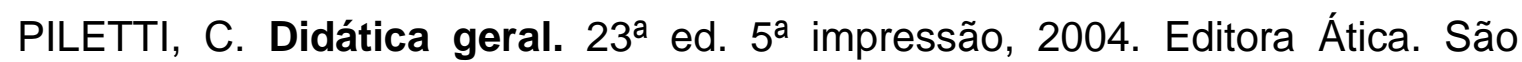
Paulo, São Paulo, p.64.

ROSA, P.R.S. Instrumentação para o ensino de Ciências. Departamento de Física Universidade Federal Campo Grande - Mato Grosso do Sul, p.123.

SANTOS, V.M.N; JACOBI, P.R. Formação de professores e cidadania: projetos escolares no estudo do ambiente. Educação e Pesquisa. São Paulo, v. 37, n. 2, p. 263-278, ago. 2011.

SCHALL, V.T. Environmental and health education for school-age children: A transdisciplinary approach. Cad. Saúde Pública, Rio de Janeiro, v. 10, n. 2, p. 259-263, Jun. 1994.

SAUVÉ, L. Educação Ambiental e Desenvolvimento Sustentável: uma análise complexa. Revista de Educação Pública, vol. 10, jul/dez, 1997.

SILVA,D, M.P. Percepção de educadores da rede pública de ensino de Itaporanga D'Ajuda-SE. Dissertação de mestrado Universidade Federal de Sergipe, 2008.

SOARES,M, B; FRENEDOZO, R, C. Educação Ambiental: Concepções e práticas de professores da cidade de Santo André (SP). Anais do VII Encontro Nacional de Pesquisa de Educação em Ciências, Florianópolis, nov. 2009. Disponível em: <http://posgrad.fae.ufmg.br/posgrad/viienpec/pdfs/124.pdf> . Acesso em: 26 set. 2014.

TOZONI-REIS, M.F.C. Formação dos educadores ambientais e paradigmas em transição. Ciência \& Educação. (Bauru), v. 8, n. 1, p. 83-96, 2002.

TOZONI-REIS, M. F. de C. Temas ambientais como "temas geradores": Contribuições para uma metodologia educativa ambiental crítica, transformadora e emancipatória. Educar em Revista. Curitiba, n. 27, p. 93-110, out. 2006.

VALENTIN, L; SANTANA, L, C. Concepções e práticas de educação ambiental de professores de uma escola pública. Ciência \& Educação. (Bauru), Bauru, v. 16, n. 2, p. 387-399, 2010. 